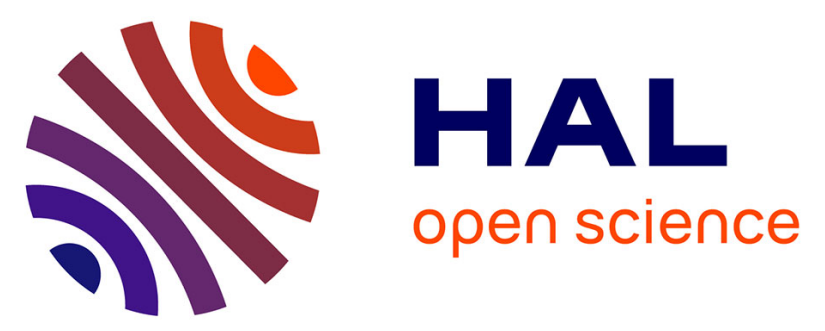

\title{
Translation and cross-cultural validation of the French version of the Sleep-Related Breathing Disorder scale of the Pediatric Sleep Questionnaire
}

\author{
Laurence Jordan, Nicole Beydon, Noéline Razanamihaja, Pascal Garrec, \\ Maria Clotilde Carra, Benjamin P. Fournier, Brigitte Vi-Fane, Stéphane \\ Kerner, Rufino Felizardo, Marie-Laure Boy-Lefèvre, et al.
}

\section{To cite this version:}

Laurence Jordan, Nicole Beydon, Noéline Razanamihaja, Pascal Garrec, Maria Clotilde Carra, et al.. Translation and cross-cultural validation of the French version of the Sleep-Related Breathing Disorder scale of the Pediatric Sleep Questionnaire. Sleep Medicine, 2019, 58, pp.123 - 129. 10.1016/j.sleep.2019.02.021 . hal-03486422

\section{HAL Id: hal-03486422 \\ https://hal.science/hal-03486422}

Submitted on 20 Dec 2021

HAL is a multi-disciplinary open access archive for the deposit and dissemination of scientific research documents, whether they are published or not. The documents may come from teaching and research institutions in France or abroad, or from public or private research centers.
L'archive ouverte pluridisciplinaire HAL, est destinée au dépôt et à la diffusion de documents scientifiques de niveau recherche, publiés ou non, émanant des établissements d'enseignement et de recherche français ou étrangers, des laboratoires publics ou privés.

\section{(ㄷ)(1) $\$$}

Distributed under a Creative Commons Attribution - NonCommerciall 4.0 International 


\section{Translation and Cross-cultural validation of the French version of the Sleep-Related Breathing Disorder scale of the Pediatric Sleep Questionnaire}

Laurence Jordan ${ }^{1-2-3} *$, Nicole Beydon ${ }^{4}$, Noéline Razanamihaja ${ }^{1}$, Pascal Garrec ${ }^{1-2}$, Maria Clotilde Carra $^{1-5}$, Benjamin P Fournier ${ }^{1-2-6}$, Brigitte Vi-Fane ${ }^{1-2}$, Stéphane Kerner ${ }^{1-2}$, Rufino Felizardo ${ }^{1-2}$, Marie-Laure Boy-Lefèvre ${ }^{1-2}$, Muriel De La Dure-Molla $a^{1-2-7}$

1- Paris Diderot University, Sorbonne Paris Cité, Paris, France

2- Reference Center for Oral and Dental Rare Diseases, Rothschild hospital, AP-HP, Paris, France

3 - Structural Metallurgy Unit, IRCP UMR 8247, Chimie ParisTech, Paris, France

4- Department of Functional Respiratory Exploration and Sleep Center, Armand Trousseau hospital, Paris, France

5- Department of Periodontology, Rothschild hospital and Population-based Epidemiologic Cohorts Unit, UMS 011, Villejuif, France

6- Molecular Oral Pathophysiology, Cordeliers Center Recherche, UMR S1163, Paris, France

7- Molecular and Physiopathological bases of Osteochondrodysplasia, Imagine institute, UMR-S1163, Paris, France

\section{Abstract}

Background: Sleep-disordered breathing (SDB), including obstructive sleep apnea syndrome, is often underestimated because it requires a burdensome test (polysomnography) to ensure diagnosis. To improve polysomnography referral, it is of utmost importance to validate efficient alternative screening tools. This study aimed to provide a translation and a cross-cultural validation of the Pediatric Sleep Questionnaire (PSQ) into French to obtain an easy-to-use and reliable screening tool. The psychometric properties of the French version were also determined.

Methods: The process of cross-cultural adaptation was carried out following these steps: forward-backward translation, evaluation by an expert committee, and pretesting of the prefinal version. Reliability of the French-PSQ version was assessed by Cronbach's alpha coefficients and Spearman's correlation on a convenient sample of 201 children (aged between two and 17 years). Construct validity was determined by factor analysis of principal components.

Results: Internal consistency was within an adequate range for all subscales: 0.711 for snoring, 0.559 for sleepiness, 0.682 for behavioral problems, and 0.776 for the whole questionnaire. Spearman's correlation analysis comparing questionnaires administered two weeks apart showed good correlation coefficients for all subscales (snoring: 0.642, sleepiness: 0.846, 
behavioral problems: 0.780 , and entire SRBD scale: 0.835 ). Factor analysis performed to assess the structure of the French-SRBD scale confirmed the same four factors described in the original questionnaire ("breathing," "behavior," "sleepiness," and "other").

Conclusion: The French version of the PSQ has been successfully cross-culturally adapted and showed good psychometric properties, suggesting that it is useful as a tool to screen sleepdisordered breathing in French-speaking children.

\footnotetext{
* Corresponding author: laurence.jordan@univ-paris-diderot.fr Keywords: obstructive sleep apnea, Pediatric Sleep Questionnaire, cross-cultural adaptation, reliability, validation
}

\section{Introduction}

Obstructive sleep apnea (OSA) is characterized by repetitive episodes of prolonged partial upper airway obstruction and/or intermittent complete obstruction that disrupts normal ventilation during sleep [1]. The reported prevalence of pediatric OSA ranges from $1 \%$ to $4 \%$, although it is very likely underestimated because of a high proportion of undiagnosed cases [2]. Untreated sleep-disordered breathing (SDB) can have serious effects in young patients, leading to growth failure $[3,4]$, neurocognitive deficits with learning delays $[5,6]$, and behavioral disorders (inattention and hyperactivity) $[7,8]$. A large number of both daytime and nighttime clinical signs and symptoms are used to evaluate the possibility of sleep disorders in children, of which the most common etiology is adenotonsillar hypertrophy. The reference standard for the diagnosis and assessment of SDB is nighttime polysomnography (PSG) recording $[9,10]$. Most of the time, PSG requires an overnight stay at a sleep laboratory to monitor the electrical activity of the brain, movements of facial muscles and eyes, and respiratory activity. However, PSG is time-consuming, expensive, or not always available. Questionnaires have been developed to assess sleep disorders in children. According to the literature, these questionnaires are useful, easy-to-use, reliable, and inexpensive. Moreover, they are adapted to screen children for OSA in clinical and epidemiological studies. Additionally, they often represent the only means to collect data about past medical history and current elements that can range from simply isolated snoring to obstructive sleep apnea. The questionnaire survey may allow for a preselective sorting of candidates for polysomnography. 
According to the European Respiratory Society Task Force on SDB diagnosis and management, if PSG is not available, it is possible to use validated questionnaires such as the Pediatric Sleep Questionnaire (PSQ) or the Sleep Clinical Record [11]. The PSQ, and in particular the SleepRelated Breathing Disorder (SRBD) scale developed by Chervin and colleagues, correctly classify $86 \%$ of cases. This questionnaire takes into account diurnal and nocturnal symptoms, along with neurobehavioral complications of OSA $[12,13]$. Authors agree that the validated PSQ has a diagnostic accuracy sufficient to be used as a screening tool for SDB $[10,14,15]$. Translated into Spanish [16], Turkish [17], Malaysian [18], Chinese [19] and Portuguese [20], this widely used questionnaire has not yet been translated into and validated in French.

This study aimed to validate the translated and culturally adapted version of the PSQ-SRBD scale on a cohort of French children.

\section{Methods}

\subsection{The instrument/questionnaire}

The original version of the PSQ or the SRBD scale is a questionnaire that can be autoadministered to parents of children aged 2-18 years. It consists of 22 closed-response questions based on the prominent symptom-complexes of sleep disorders including snoring, daytime sleepiness, and inattentive or hyperactive behavior. Three subscales of the SRBD questionnaire have also been validated: "snoring" (items 1 to 4), "sleepiness" (items 10 to 13) and "behavior" (items 17 to 22 ). The SRBD scale showed a sensitivity of $81 \%$ and a specificity of $87 \%$ to detect children with OSA [12].

Possible answers include "yes," "no" or "don't know," which are weighted as 1, 0, or missing, respectively. The overall score is obtained by calculating the mean of the scores of all items excluding the missing items. The optimal threshold value has been set at 0.33 (cutoff value: $33 \%$ of 22 questions answered positively). Thus, a score greater than 0.33 is considered positive and suggests the presence of pediatric SDB [12].

\subsection{Study population}

In this cross-sectional study, the sample was selected by convenience and included parents of children aged 2 - 17 years admitted to the Odontology Center of the Rothschild Hospital (Assistance Publique - Hôpitaux de Paris) for dental care in pediatric dentistry (general population without particular risk factors) from April 2015 to October 2016. Only children 
whose parents perfectly understand French were eligible for inclusion. Children with craniofacial malformation, neuromuscular diseases, and chronic respiratory pathology, including asthma, were excluded. To calculate the sample size, we applied the rule of two to 20 subjects per item ratio recommended by Kline [21]. Terwee et al. also recommended a sample size greater than 100 to be adequate [22]. Therefore, we chose to select ten subjects per item, which involved the recruitment of 220 children to test the questionnaire. In comparison, Chervin et al. validated the SRBD scale with 162 subjects [12].

\subsection{Translation and cross-cultural adaptation of the PSQ/SRBD}

This process consisted of two phases: the translation of the PSQ/SRBD into French and its validation in a French pediatric cohort. The cross-cultural adaptation is aimed to maximize the attainment of semantic and conceptual equivalence between different language questionnaires. Thus, the version resulting from the translations fulfilled four criteria: clarity of the translation, use of vocabulary accessible to all (avoiding technical terms), use of correct grammatical terms, and neutral style and conceptual equivalence in line with the content of the original questionnaire. This process was carried out following steps recommended by Beaton et al. [23] including 1) forward translation of the questionnaire from English into French by two translators; 2) synthesis of the two translations; 3) back-translation; 4) evaluation by an expert committee; and 5) pretesting of the penultimate version.

Two native French translators who were perfectly bilingual translated each item of the English version of the SRBD scale independently. A committee compared the two translations, and differences were discussed. The translation process favored a conceptual rather than a literal translation and resulted first in a consensual French version of the questionnaire. Then, this version was subsequently back-translated into English by two independent translators who were blind to the original English version. Next, the committee compared the two backtranslations to the original questionnaire to verify the literal, conceptual, and semantic equivalences. Very few discrepancies were found, which indicated a satisfactory backtranslation, and a pre-final version of the questionnaire was obtained. This penultimate version was pretested on twenty parents by two investigators to assess clarity, appropriateness, and cultural relevance (i.e., appropriate cultural adaptation). During this evaluation, one investigator asked questions, while the other investigator noted respondents' remarks on the 
items to evaluate their understanding. After a few minor adjustments, the French version of the SRBD scale was finalized (Appendix A).

\subsection{Ethics approval}

Permission to translate the SRBD scale into French was obtained from the first author (RD Chervin) and the University of Michigan, USA. This study was declared to the National Commission for Data Protection and Liberties (CNIL-France) and approved by the Research Project Ethics Evaluation Committee of the Robert Debré hospital in Paris ( ${ }^{\circ}:$ 2016/281-2). An information note was provided to each parent who signed a consent form to participate in this study. Parents were instructed to anonymously self-complete the questionnaire.

\subsection{Statistical analysis and validation}

The data sets were analyzed using SPSS (Statistical Package for Social Science), version 24.0 (SPSS, Inc., USA). P-values < 0.05 were considered to be statistically significant. Descriptive analyses of the study population were performed. Data are expressed as the mean and standard deviation or median and range. Occasional missing answers or response of "don't know" were ignored because these comprised less than $10 \%$ of the responses [24].

The psychometric properties of the French-SRBD scale were determined in order to evaluate its performance. In the present study, we assessed the internal consistency, reliability, and testretest reliability of the French-SRBD. Moreover, we tested the content and construct validity of the PSQ/SRBD. For reliability, the internal consistency of each scale was calculated using Cronbach's alpha [25], which measured the average correlation coefficient between each item and the scale. A value $\geq 0.7$ indicated adequate reliability, 0.5 to 0.7 moderate, 0.2 to 0.4 fair, and $\leq 0.2$ low reliability according to the recommendations of Nunnally and Bernstein for group comparisons. The cohesion of the questionnaire was evaluated from the correlation between subscales and between each subscale and the total of items [26]. The temporal stability of item responses was evaluated by test-retest reliability. Sixty-six parents completed the questionnaire twice, 15 days apart. Test-retest was evaluated using Spearman's correlation coefficient.

Content validity was assessed by a qualified pediatric pulmonologist (i.e., it was verified that the items translated into French were relevant and correctly reflected the different aspects of sleep-disordered breathing). The correlations between the items and the entire questionnaire 
or the different subscales were tested using Pearson's correlation coefficient test. A value greater than 0.3 was considered a moderate correlation, whereas 0.8 and above was considered a strong correlation [27].

Construct validity was determined by confirmatory factor analysis of principal components with oblique rotation (Promax). Principal Component Analysis (PCA) is the most widely used extraction method and the most appropriate when the objective is to reduce the number of items to a smaller number of representative factors [12,28]. According to Hair et al., oblique rotation is more flexible and realistic because the theoretically underlying factors are not assumed to be uncorrelated with each other [24].

\section{Results}

\subsection{Translation and Adaptation of the SRBD scale}

The translation/back-translation process did not lead to any major difficulties. The committee discussed only two items that could be better adapted to context or French expression. Question 19, "is easily distracted by extraneous stimuli" became "is easily distracted by everything going on around him," and question 21 "driven by a motor" became "comme une pile" (like a battery). During the pretest, the French version of the questionnaire did not raise questions from parents.

\subsection{Characteristics of the study population}

We included 220 parents, 19 of which ultimately did not complete the questionnaire $(91.4 \%$ participation). The study sample consisted therefore of 201 parents; the mean age (SD) of their children (104 girls (51.7\%) and 97 boys (58.3\%)) was 6.3 (2.8) years. The majority of respondents were the children's mother, at $78.1 \%$.

Overall, the rate of "don't know" responses was $2.2 \%$ on average for the 22 questions, ranging between 0 and $7 \%$ depending on the items.

The calculation of body mass index [29] revealed that $79.3 \%$ of children had normal body weight, $12 \%$ were overweight, and $8.6 \%$ were obese (Table 1). Descriptive data of all FrenchSRBD items are presented in Table 2.

Table 1: Characteristics of the sample

Characteristics $\mathrm{n}(\%)$




\begin{tabular}{ll}
\hline $\begin{array}{l}\text { Gender, } \mathbf{n} \text { (\%) } \\
\text { Male }\end{array}$ & $97(48.3)$ \\
Female & $104(51.7)$ \\
& \\
Age, years & \\
Mean \pm SD & $6.29 \pm 2.8$ \\
Median & 6.00 \\
Range & $2-16$ \\
& \\
Parents, $\mathbf{n}$ (\%) & \\
Father & $42(20.9)$ \\
Mother & $157(78.1)$ \\
Legal representative & $2(1.0)$ \\
& \\
Body Mass Index, $\mathbf{n}(\%)$ & \\
Normal & $92(79.3)$ \\
Overweight & $14(12.1)$ \\
Obesity & $10(8.6)$ \\
\hline
\end{tabular}

Table 2: Descriptive statistics for items of the French-SRBD $(n=201)$

\begin{tabular}{rrlr}
\hline & & Items & Yes n (\%) \\
\hline 1 & A2 & Snore more than half the time & $41(20.4)$ \\
2 & A3 & Always snore & $8(4)$ \\
3 & A4 & Snore loudly & $30(14.9)$ \\
4 & A5 & Have “heavy" or loud breathing & $46(22.9)$ \\
5 & A6 & Have trouble breathing, or struggle to breathe & $8(4)$ \\
6 & A7 & Stop breathing during the night & $8(4)$ \\
7 & A24 & Tend to breathe through the mouth during the day & $36(17.9)$ \\
8 & A25 & Have a dry mouth on waking up in the morning & $45(22.4)$ \\
9 & A32 & Occasionally wet the bed & $63(31.3)$ \\
10 & B1 & Wake up feeling unrefreshed in the morning & $86(42.8)$ \\
11 & B2 & Have a problem with sleepiness during the day & $30(14.9)$ \\
12 & B4 & Has a teacher commented that your child appears & $22(10.9)$ \\
13 & B6 & It is hard to wake your child up in the morning & $58(28.9)$ \\
14 & B7 & Does your child wake up with headaches in the & 8 morning \\
& & Did your child stop growing at a normal rate at any & $11(5.5)$ \\
15 & B9 & time since birth & $11(5.5)$ \\
16 & B22 & Is your child overweight & $60(29.9)$ \\
17 & C3 & Does not seem to listen when spoken to directly & $43(21.4)$ \\
18 & C5 & Has difficulty organizing tasks and activities & $104(51.7)$ \\
19 & C8 & Is easily distracted by extraneous stimuli & $54(26.9)$ \\
20 & C10 & Fidgets with hands or feet or squirms in seat & $78(38.8)$ \\
21 & C14 & Is “on the go" or often acts as if "driven by a motor" \\
22 & C18 & Interrupts or intrudes on others & $84(41.8)$ \\
\hline
\end{tabular}




\subsection{Reliability of the French-SRBD scale}

The French-SRBD scale showed an adequate level of internal consistency, with a Cronbach's alpha coefficient of 0.776 for the total items, 0.711 for the snoring scale, 0.559 for the sleepiness scale, and 0.682 for the behavioral problems scale (Table 3 ). Regarding the longterm stability of the questionnaire, the correlation between the test and re-test was significant. Spearman's correlation coefficients were 0.835 for the total SRBD scale $(p<0.005), 0.642$ for the snoring scale $(p<0.005), 0.846$ for the sleepiness scale $(p<0.005)$, and 0.780 for the behavioral problems scale $(p<0.005)$.

Table 3: Scoring internal consistency and test-retest reliability

\begin{tabular}{lcc}
\hline & $\begin{array}{c}\text { Cronbach's } \\
\text { Alpha } \\
\text { (consistency) }\end{array}$ & $\begin{array}{c}\text { Spearman's } \\
\text { Correlation* } \\
\text { (test-retest) }\end{array}$ \\
\cline { 2 - 3 } French-SRBD scales & $\mathrm{n}=201$ & $\mathrm{n}=66$ \\
\hline Snoring (4 items) & 0.711 & 0.642 \\
Sleepiness (4 items) & 0.559 & 0.846 \\
Behavior (6 items) & 0.682 & 0.780 \\
VF-SRBD (22 items) & 0.776 & 0.835 \\
\hline${ }^{*} \mathrm{p}<0.005$ & &
\end{tabular}

\subsection{Construct validity of the French-SRBD scale}

The Pearson's correlation coefficients of the four items of snoring and sleepiness subscales as well as the six items of the behavior scale were significant (Table 4).

Table 4: Pearson's correlation coefficients

\begin{tabular}{ccc}
\hline & & $\begin{array}{c}\text { Pearson's } \\
\text { correlation* }\end{array}$ \\
\cline { 3 - 3 } item & Snoring (4 items) & $\mathrm{n}=201$ \\
1 & A2 $\quad$ Snore more than half the time & 0.838 \\
2 & A3 $\quad$ Always snore & 0.586 \\
3 & A4 $\quad$ Snore loudly & 0.765 \\
4 & A5 $\quad$ Have “heavy" or loud breathing & 0.686 \\
& & \\
& Sleepiness (4 items) & 0.767 \\
10 & B1 $\quad$ Wake up feeling unrefreshed in the morning & 0.602 \\
11 & B2 $\quad$ Have a problem with sleepiness during the day & 0.527 \\
12 & B4 Your child appears sleepy during the day & 0.713 \\
13 & B6 $\quad$ It is hard to wake your child up in the morning &
\end{tabular}




\section{Behavior (6 items)}

17 C3 Does not seem to listen when spoken to directly 0.624

18 C5 Has difficulty organizing tasks and activities $\quad 0.537$

19 C8 Is easily distracted by extraneous stimuli 0.687

20 C1 Fidgets with hands or feet or squirms in seat $\quad 0.598$

210 Is "on the go" or often acts as if "driven by a $\quad 0.660$

22 C1 motor" 0.547

4 Interrupts or intrudes on others

C1

8

$* p<0.005$

Before the application of the factor analysis, it was statistically verified that the data matrix had enough correlations; to do that, Bartlett's test of sphericity, a statistical test for the presence of correlations among the variables, and the measure of sampling adequacy (Kaiser-Meyer-Olkin index) were applied. The calculation of the Kaiser-Meyer-Olkin (KMO) index confirmed sampling adequacy, with a value of 0.721 . Bartlett's test of sphericity was significant $(\chi 2=796.075 ; \mathrm{df}=$ $231 ; p<0.005)$ indicating that the correlation matrix is suitable for factoring.

Before rotation, factor analysis by the principal components method revealed seven factors with an eigenvalue greater than 1, explaining $61.16 \%$ of the cumulative variance. After rotation, the final number of factors to be retained was based on the following three criteria (Figure 1): factors with eigenvalues greater $\geq 1$, scree plot (extracted factors must be before inflection and eigenvalue $>1$ ), and a predetermined number of factors based on documented factor structure $[24,28,30,31]$. We took these considerations into account; then, to confirm the presence of factors already known to and described by Chervin et al. in their original questionnaire, four factors were extracted and then compared to the factors of the original questionnaire, and named accordingly [12]. 


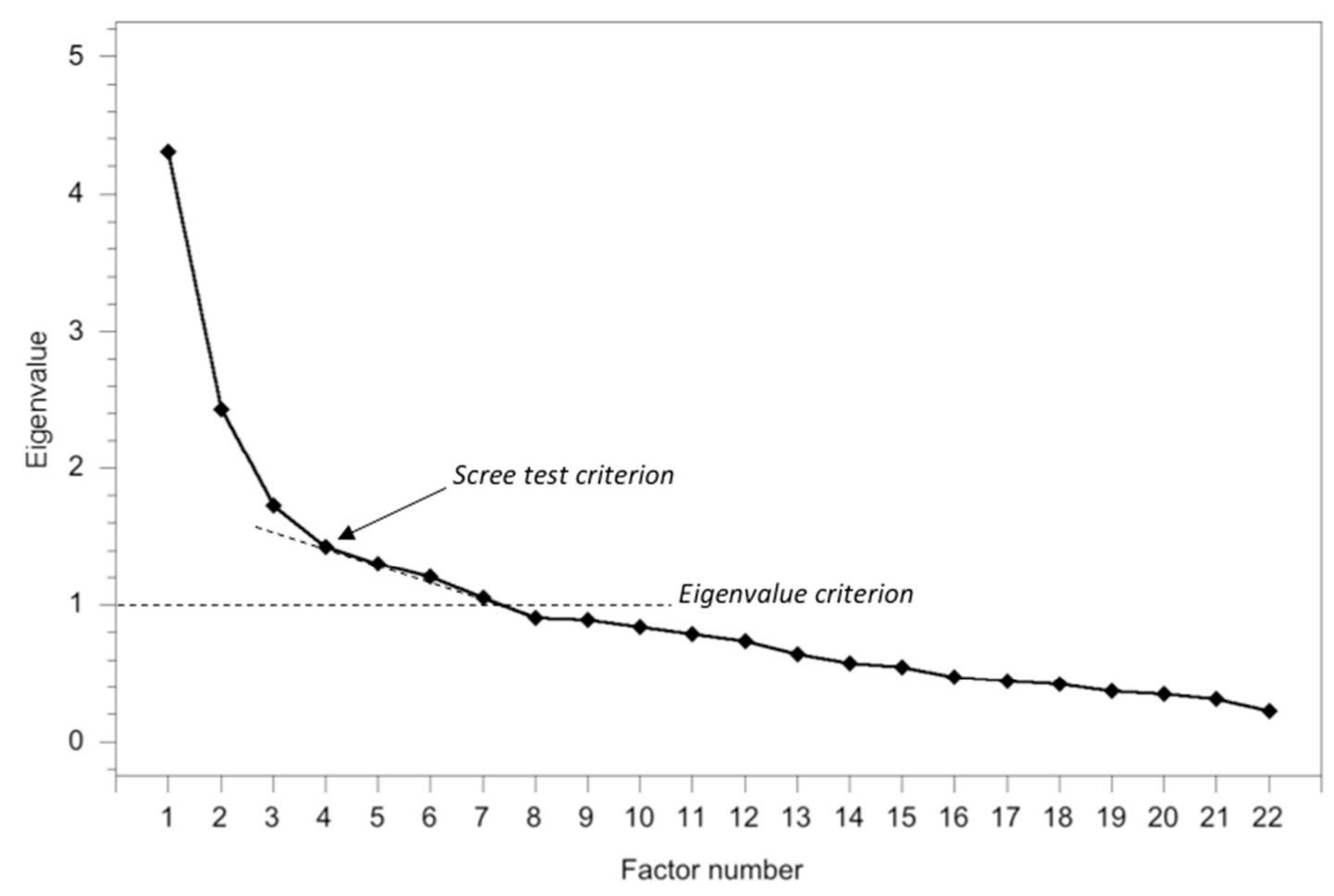

Figure 1: Factor analysis of principal components, scree plot of eigenvalues

Factor structure is shown in Table 5, and the majority of the items presented the highest loading weight in the domains allocated by Chervin et al. [12] in the original questionnaire: "breathing," "behavior," "sleepiness" and "other."There were two differences between the factors of the original questionnaire and the translated version. In the French version, the item "is your child overweight" belonged to the domain "breathing" (instead of "other" in the original version), while the item "does your child wake up with headaches in the morning" belonged to the factor "sleepiness" (instead of "breathing" in the original scale). All items belonged to only one factor, except two items that saturated with a significant close value with the right factors. Item C5 correlated with factor 3; however, the logic of these factors allowed this item to be regarded as belonging to factor 2 . The same reasoning could be followed for item A24, which correlated with factor 1 instead of factor 4.

Table 5: Factor structure of the French-SRBD questionnaire

\begin{tabular}{|c|c|c|c|c|c|}
\hline \multirow{2}{*}{\multicolumn{2}{|c|}{ French-SRBD items }} & \multirow{2}{*}{$\begin{array}{c}\text { Factor } 1 \\
\text { breathin } \\
g\end{array}$} & \multirow{2}{*}{$\begin{array}{l}\text { Factor } 2 \\
\text { behavior } \\
\end{array}$} & \multirow{2}{*}{$\begin{array}{c}\text { Factor } 3 \\
\text { sleepines } \\
s\end{array}$} & \multirow{2}{*}{$\begin{array}{c}\text { Factor } 4 \\
\text { other }\end{array}$} \\
\hline & & & & & \\
\hline $\mathrm{A} 2$ & Snore more than half the time & 0.784 & & & \\
\hline A6 & Have trouble breathing, or struggle to breathe & 0.712 & & & \\
\hline A4 & Snore loudly & 0.663 & & & \\
\hline
\end{tabular}


A3 Always snore

A7 Stop breathing during the night

A5 Have "heavy" or loud breathing

B22 Is your child overweight

A25 Have a dry mouth on waking up in the morning

A24 Tend to breathe through the mouth during the day

C8 Is easily distracted by extraneous stimuli

C14 Is "on the go" or often acts as if "driven by a motor"

C3

Does not seem to listen when spoken to directly

C18 Interrupts or intrudes on others

C10 Fidgets with hands or feet or squirms in seat

C5 Has difficulty organizing tasks and activities

B7

Does your child wake up with headaches in the morning

B4

Has a teacher commented that your child appears sleepy during the day

B2 Have a problem with sleepiness during the day

B6 It is hard to wake your child up in the morning

B1 Wake up feeling unrefreshed in the morning

A32 Occasionally wet the bed

B9
Did your child stop growing at a normal rate at any time since birth
0.635

0.554

0.542

0.469

0.445

0.357

0.411

0.737

0.672

0.611

0.553

0.506

0.326

0.462

0.755

0.741

0.679

0.777

0.766

0.296

0.252

* Items in bold present highest loading as in the original version; items in italic indicate highest loading on other factors than the original; items with a gray background designate items saturating with a significant close value with the good factor.

We calculated the questionnaire score of each participant as the mean (SD). The French-SRBD scale score was $0.216(0.16)$, ranging between 0 and 0.773 . The distribution of respondents by percentage of scores showed that $19.9 \%$ of children scored $\geq 0.33$ (cutoff value).

\section{Discussion}

The SRBD is an instrument used to screen for OSA even though PSG remains the current reference standard for diagnosis. However, given that the use of PSG is restrictive, it is important to have a valid and more accessible screening tool. The performance of the SRBD scale to reveal signs of SDB was proven by the authors (Chervin et al.) with significantly high 
sensitivity (0.85) and specificity (0.87). The PSQ questionnaire has been adapted to other languages [16-20] and has demonstrated its utility on childhood OSA.

The present study described the cross-cultural adaptation and validation of the French version of the SRBD scale. In this process, we followed the international recommendations for transcultural adaptation [23]. Indeed, while translating the questionnaire, it was necessary to adapt items 19 and 21 because of different cultural expressions without changing the meaning, like the Malaysian version [18].

The French-SRBD scale showed adequate internal consistency with a correct Cronbach alpha value for the four subscales. Similar results were found for the reliability of the Spanish, Turkish, Malaysian, Chinese and Portuguese versions of the questionnaire and as reported by Chervin et al. for the original version $[12,16,17,18,19,20]$. Test-retest reliability of the questionnaire, evaluated by Spearman's correlation was high, suggesting that the scores remained stable over two weeks. These results were similar to those reported by Chervin et al. and in the Malaysian, Chinese and Portuguese adaptations $[12,18,19,20]$. These results allow us to consider that the French-SRBD is reliable.

A Pearson's correlation was run to assess the relationship between the items and the subscales. There was a strong correlation between the items of each subscale, indicating good validity of the linguistic constructs.

Factor analysis has shown that the questionnaire could be divided into the same dimensions as the original American SRBD ("breathing," "behavior," sleepiness" and "other"). In our validation study, there were slight differences between the results of the factor analysis of the FrenchSRBD and the original version, similar to what was observed with the Chinese version [19]. It can be assumed that these minor differences were related to linguistic and cultural specificities [12]. The other foreign adaptations did not evaluate construct validity by factor analysis.

Adenotonsillar hypertrophy is the primary cause of OSA. However, apart from this etiology, SDB symptoms are common in pediatric populations with congenital craniofacial anomalies and syndromes or with moderate craniofacial problems such as vertical growth direction, mandibular retrognathia or hyperdivergence, maxillary endognathia or retrognathia, and a narrow ogival palate $[32,33,34,35]$. Dentists and orthodontists who see children regularly are 
therefore particularly well placed to identify the symptoms of SDB, especially if the clinical examination is associated with the SRBD-scale.

Thus, the French-SRBD questionnaire is a reliable screening tool that can be used by dentists or orthodontists to improve the referral process to sleep specialists.

The present study has some strengths and limitations. We applied a strict protocol of backtranslation as described by Beaton et al. 2000 [23] to translate into French the original SRBD questionnaire, we carried out a complete cross-cultural adaptation of the questionnaire, we tested its content and construct validity, and we validated its internal consistency and reliability. However, we did not validate the diagnostic accuracy of the questionnaire, in terms of sensibility and specificity against a gold standard (e.g., polysomnography). This definitely represents an objective for further research. Moreover, future studies in different populations (e.g., age) should verify the psychometric properties of this instrument.

\section{Conclusion}

In conclusion, the French-SRBD scale has been successfully translated and cross-culturally adapted. It showed similar psychometric properties as the original English questionnaire, with the same factorial structure, suggesting that it may be used to assess SDB in French pediatric populations. Future studies will determine the relevance of the use of this translated questionnaire.

\section{Acknowledgments}

We would like to acknowledge all the patients who dedicated time to this study and Alexia Constantini, Aurélie Baloul, and Anne-Gaëlle Capitaine for assisting in data collection.

\section{Conflicts of interest}

The authors declare that they have no conflicts of interest. 


\section{References}

1. American Thoracic Society. Standards and indications for cardiopulmonary sleep studies in children. Am J Respir Crit Care Med 1996; 153: 866-878.

2. Lumeng JC, Chervin RD. Epidemiology of pediatric obstructive sleep apnea. Proc. Am. Thorac Soc 2008; 5: 242-252.

3. Bonuck KA, Freeman K, Henderson J. Growth and growth biomarker changes after adenotonsillectomy: systematic review and meta-analysis. Arch Dis Child. 2009; 94(2): 83-91.

4. Katz ES, Moore RH, Rosen CL, Mitchell RB, Amin R, Arens R, et al. Growth after adenotonsillectomy for obstructive sleep apnea: an RCT. Pediatrics. 2014; 134(2): 282-9.

5. Gozal D. Sleep-disordered breathing and school performance in children. Pediatrics. 1998; 102: 616-620.

6. Bourke R, Anderson V, Yang JS, Jackman AR, Killedar A, Nixon GM, Davey MJ, Walker AM, Trinder J, Horne RS. Cognitive and academic functions are impaired in children with all severities of sleep-disordered breathing. Sleep Med. 2011; 12: 489-496.

7. Giordani B, Hodges EK, Guire KE, Ruzicka DL, Dillon JE, Weatherly RA, Garetz SL, Chervin RD. Changes in neuropsychological and behavioral functioning in children with and without obstructive sleep apnea following Tonsillectomy. J. Int. Neuropsychol. Soc. 2012; 18: 212222.

8. Landau YE, Bar-Yishay O, Greenberg-Dotan S, Goldbart AD, Tarasiuk A, Tal A. Impaired behavioral and neurocognitive function in preschool children with obstructive sleep apnea. Pediatr. Pulmonol. 2012; 47: 180-188.

9. Wise MS, Nichols CD, Grigg-Damberger MM, Marcus CL, Witmans MB, Kirk VG, D'Andrea LA, Hoban TF. Executive summary of respiratory indications for polysomnography in children: an evidence-based review. Sleep 2011; 34(3): 389-398.

10. American Academy of Pediatrics Section on Pediatric Pulmonology, Subcommittee on obstructive sleep apnea syndrome. Clinical Practice Guideline: diagnosis and management of childhood obstructive sleep apnea syndrome. Pediatrics 2002; 109: 704-712.

11. Kaditis AG, Alonso Alvarez ML, Boudewyns A, Alexopoulos El, Ersu R, Joosten K, Larramona H, Miano S, Narang I, Trang H, Tsaoussoglou M, Vandenbussche N, Villa MP, Van Waardenburg D, Weber S Verhulst S. Obstructive sleep disordered breathing in 2 18-yearold children: diagnosis and management. Eur Respir J 2016; 47: 69-94.

12. Chervin R, Hedger K, Dillon J, Pituch KJ. Pediatric Sleep Questionnaire (PSQ): validity and reliability of scales for sleep-disordered breathing, snoring, sleepiness, and behavioral problems. Sleep Med 2000; 1: 21-32.

13. Chervin R, Weatherly R, Garetz S, Ruzicka DL, Giordani BJ, Hodges EK, Dillon JE, Guire KE. Pediatric Sleep Questionnaire: prediction of sleep apnea and outcomes. Arch Otolaryngol Head Neck Surg 2007; 133(3): 216-222. 
14. Pijpers M, Poels PJ, Vaandrager JM, de Hoog M, Van den Berg S, Hoeve HJ, Joosten KF. Undiagnosed obstructive sleep apnea syndrome in children with syndromal craniofacial synostosis. J Craniofac Surg. 2004; 15(4): 670-674.

15. De Luca Canto G, Singh V, Major MP, Witmans M, El-Hakim H, Major PW, Flores-Mir C. Diagnostic capability of questionnaires and clinical examinations to assess sleep-disordered breathing in children: a systematic review and meta-analysis. J Am Dent Assoc. 2014; 145(2): 165-178.

16. Tomàs Vila $M$, Miralles Torres A, Beseler Soto B. Versión española del Pediatric Sleep Questionnaire (PSQ). Un instrumento útil en la investigación de los trastornos del sueño en la infancia. Análisis de su fiabilidad. An Pediatr 2007; 66(2): 121-128.

17. Yüksel H, Söğüt A, Yilmaz Ö, Kutluay E. Reliability and validity of the Turkish version of the pediatric sleep questionnaire: a tool for prediction of sleep related breathing disorder. Tüberk Toraks 2011; 59(3): 236-241.

18. Hasniah AL, Jamalludin AR, Norrashidah AW, Norzila MZ, Asiah K, Anida AR, Fadzil AA, Ramli $Z$, Samsinah H. Cross-cultural adaptation and reliability of pediatric sleep questionnaire in assessment of sleep-disordered breathing in the Malay speaking population. World J Pediatr 2012; 8(1): 38-42.

19. Wang $\mathrm{CH}$, Yang $\mathrm{CM}$, Huang YS. The validation and reliability of Chinese version of the Pediatric Sleep Questionnaire for patients with sleep breathing problem. Taiwan J Psychiatry 2012; 26(3): 177-186.

20. Certal V, Flor de Lima F, Winck J, Azevedo I, Costa-Pereira A. Translation and cross-cultural adaptation of the Pediatric Sleep Questionnaire into Portuguese language. Int J Pediatr Otorhinolaryngol 2015; 79(2): 175-178.

21. Kline P. Psychometrics and Psychology. London: Academic Press, 1979 381p.

22. Terwee CB, Mokkink LB, Knol DL, Ostelo RW, Bouter LM, de Vet HC: Rating the methodological quality in systematic reviews of studies on measurement properties: a scoring system for the COSMIN checklist. Qual Life Res. 2012; 21(4): 651-657.

23. Beaton DE, Bombardier C, Guillemin F, Ferraz MB. Guidelines for the process of crosscultural adaptation of self-report measures. Spine 2000; 25(4): 3186-3191.

24. Hair Jr JF, Black WC, Babin BJ, Anderson RE. Multivariate Data Analysis. 7th ed. Harlow: Pearson; 2014.

25. Cronbach LJ. Coefficient alpha and the internal structure of tests. Psychometrika. 1951; 16(3): 297-334.

26. Nunnally JC, Bernstein IH. Psychometric theory (3rd ed.). New York, McGraw-Hill, Inc. 1994.

27. Cohen J. Statistical Power Analysis for the Behavioral Sciences, 2nd ed. Hillsdale, NJ: Erlbaum, 1988. 
28. Beavers AS, Lounsbury JW, Richards JK, Huck SW, Skolists GJ, Esquivel SL. Practical considerations for using exploratory factor analysis in educational Research. Practical Assessment, Research \& Evaluation. 2013 ; 18(6): 1-13.

29. Cole TJ, Bellizzi MC, Flegal KM, Dietz WH. Establishing a standard definition for child overweight and obesity worldwide: international survey. BMJ. 2000; 320(7244): 1240-1243.

30. Cattell RB. The Scree test for the number of factors. Multivariate Behavioral Research 1966; 1: 245-276.

31. Cattell RB, Vogelman S. A comprehensive trial of the scree and KG criteria for determining the number of factors. Multivariate Behavioral Research 1977; 12: 289-325.

32. Flores-Mir C, Korayem M, Heo G, Witmans M, Major MP, Major PW. Craniofacial morphological characteristics in children with obstructive sleep apnea syndrome: a systematic review and meta-analysis. JADA 3013; 144(3): 269-277.

33. Pirelli P, Saponara M De Rosa C, Fanucci E. Orthodontics and obstructive sleep apnea in children. Med Clin North Am 2010; 94(3): 517-529.

34. Guilleminault C, Huang YS. From oral facial dysfunction to dysmorphism and the onset of pediatric OSA. Sleep Med Rev 2018; Aug 40: 203-214.

35. Moraleda-Cibrián M, Edwards SP, Kasten SJ, Berger M; Buchman SR, O’Brien LM. Symptoms of sleep disordered breathing in children with craniofacial malformations. J Clin Sleep Med 2014; 10(3):307-312. 


\section{Questionnaire pédiatrique sur les troubles du sommeil liés à la respiration}

Nom de l'enfant: Identifiant $\mathbf{N}^{\circ}$ :

Nom de la personne remplissant le questionnaire: Date :

A lire avant de remplir:

Merci de répondre à ces questions concernant le comportement de votre enfant pendant son sommeil et lorsqu'il est réveillé. Ces questions portent sur le comportement général de votre enfant au cours du dernier mois, et pas nécessairement au cours des derniers jours, car son comportement a pu être inhabituel s'il n'était pas en forme dernièrement. Entourer la bonne réponse ou écrivez en toutes lettres lisiblement votre réponse dans l'espace disponible. "O" signifie "oui", "N" signifie "non" et "NSP" signifie "ne sais pas".

1. Pendant son sommeil, votre enfant :

Ronfle plus de la moitié du temps?

Ronfle tout le temps?

Ronfle bruyamment?

Respire fort?

Respire avec difficulté ?

Oui Non Ne Sais Pas

O N NSP

$\mathrm{O} N \mathrm{NSP}$

$\mathrm{N} \quad \mathrm{NSP}$

$\mathrm{N} \quad \mathrm{NSP}$

$\mathrm{N} \quad \mathrm{NSP}$

2. Avez-vous déjà vu votre enfant s'arrêter de respirer pendant la nuit ? $\ldots \ldots \mathrm{O} \quad \mathrm{N} \quad \mathrm{NSP}$

3. Votre enfant :

A-t-il tendance à respirer la bouche ouverte pendant la journée?

A-t-il la bouche sèche en se réveillant le matin?

Fait-il pipi au lit quelquefois?

O N N N

O N NSP

O N NSP

4. Votre enfant :

Est-il fatigué au réveil le matin?

Est-il somnolent dans la journée?

O N NSP

O N NSP

5. Un enseignant ou un autre encadrant vous ont-ils fait la remarque que votre enfant semble avoir sommeil dans la journée?

O N NSP

6. Est-il difficile de réveiller votre enfant le matin ?

O N NSP

7. Votre enfant se réveille-t-il avec des maux de tête le matin ?

O N NSP

8. Depuis sa naissance, y a t-il eu un moment où la croissance de votre enfant a été ralentie?

9. Votre enfant est-il en surpoids ?

O N NSP

10. Souvent, votre enfant :

N'a pas l'air d'écouter quand on lui parle directement.

A du mal à organiser tâches et activités.

Est facilement distrait par tout ce qui se passe autour de lui.

Agite nerveusement ses mains ou ses pieds ou se tortille sur son siège.

Est constamment actif, est "comme une pile".

Interrompt ou s'immisce dans les discussions ou les jeux des autres.

\begin{tabular}{lll|l}
$\mathrm{O}$ & $\mathrm{N}$ & $\mathrm{NSP}$ & $\mathrm{B} 22$ \\
$\mathrm{O}$ & $\mathrm{N}$ & $\mathrm{NSP}$ & $\mathrm{C} 3$ \\
$\mathrm{O}$ & $\mathrm{N}$ & $\mathrm{NSP}$ & $\mathrm{C} 5$ \\
$\mathrm{O}$ & $\mathrm{N}$ & $\mathrm{NSP}$ & $\mathrm{C} 8$ \\
$\mathrm{O}$ & $\mathrm{N}$ & $\mathrm{NSP}$ & $\mathrm{C} 10$ \\
$\mathrm{O}$ & $\mathrm{N}$ & $\mathrm{NSP}$ & $\mathrm{C} 14$ \\
$\mathrm{O}$ & $\mathrm{N}$ & $\mathrm{NSP}$ & $\mathrm{C} 18$
\end{tabular}

MERCI BEAUCOUP! 